\title{
Aspects of the Life-Cycle of Monhystera parelegantula (Nematoda; Monhysteridae)
}

\author{
G. Vranken, L. K. Thielemans, C. Heip and M. Vandycke \\ Marine Biology Section, Zoology Institute, State University of Ghent, Ledeganckstraat 35, B-9000 Gent, Belgium
}

\begin{abstract}
Monhystera parelegantula (De Coninck, 1943) was collected from the sediment of the Sluice dock, a euhaline-polyhaline lagoon near the harbour of Ostend (Belgium). The species was cultivated in large numbers on a bacto-agar medium with bacterial growth. Embryonic growth was studied at $30{ }^{\circ} \mathrm{C}$ and $30 \% \mathrm{~S}$. Maximum embryonic length-growth occurs at the vermiform stage. Postembryonic length-growth studied at $25^{\circ} \mathrm{C}$ and $30 \% \mathrm{~S}$, is a linear function of time and may be expressed as: $l=160.46+29.55\left(t-t_{0}\right)$, where $t_{0}=$ time at the beginning of development; $t$ and $l=$ time (d) and length $(\mu \mathrm{m})$. At $25^{\circ} \mathrm{C}$ and $30 \% \mathrm{~S}$, average embryonic development time and generation time are 4 and $9 \mathrm{~d}$ respectively. Reproduction under culture conditions is parthenogenetic, but males were sometimes found. Reproduction, feeding and duration of the life cycle are discussed.
\end{abstract}

\section{INTRODUCTION}

Free-living nematodes are the most numerous animal group in the marine benthos. During the last two decades a number of species have been cultivated in various laboratories, in order to obtain information about their life cycles (for review see Kinne, 1977). Such ecological studies under artificial conditions are essential for our knowledge of several aspects of their life history, e.g. duration of embryonic development, generation time, daily growth and mortality. This is especially true for small species with a very short life cycle, such as Monhystera parelegantula, where direct field observation is impractical or impossible.

Monhystera parelegantula has been reported from widely scattered localities: the coasts of Iceland, Germany, Italy and Florida, as well as from the Black Sea, Arabian Sea and Red Sea (all single observations; Gerlach and Riemann, 1973). This paper contains the first report of this species from the Belgian coast, where it has been collected at the marine-polyhaline Sluice dock in Ostend and a polyhaline brackish water pond, the Dievengat, near Knokke.

This monhysterid is characterized by its short life cycle and its small size (length and width of a gravid female are respectively $0.42 \mathrm{~mm}$ and $0.015 \mathrm{~mm}$ ). Due to its small size the species has probably been overlooked in many faunal surveys (thus SchuurmansStekhoven, 1942, who studied the nematode fauna of the Sluice dock, does not mention it). Therefore the above list of scattered localities probably does not indicate a disjunct distribution but, on the contrary, suggests that the species is cosmopolitan.

Whatever the reason for the elusiveness of the species vis-a-vis the taxonomist, we observed that it thrives exceedingly well under laboratory conditions, quickly becoming the dominant - or one of the dominant - species in agar-cultures. The ease with which this species can be cultivated enabled us to study several aspects of its life cycle extensively

\section{MATERIAL AND METHODS \\ Extraction and Maintenance}

The nematodes were collected in the Sluice dock of Ostend (Belgium), a shallow semi-enclosed poly- to euhaline lagoon (mean depth $1.5 \mathrm{~m}$, surface $86 \mathrm{ha}$ ), connected with the North Sea through the port of Ostend. The sediment at the sampling station consists mainly of fine sand (medium grain size: $0.122 \mathrm{~mm}$, $85 \%$ sand, $13 \%$ silt and $2 \%$ gravel, mainly shell fragments). Samples were collected with an elongated meiocorer (Govaere and Thielemans, 1979). The cores were treated immediately in the laboratory. Benthic organisms and organic debris were separated from the sediment by Barnett's (1968) method, with water from 
the same habitat ( $30 \%$ S). The material extracted from the sand, which contains the animals and detritus was collected on a $38 \mu \mathrm{m}$ sieve and transferred to a Petri dish with $0.8 \%$ sterile bacto-agar Some spots of untreated sediment were placed directly in the agar ( 3 or 4 sediment-spots in a Petri dish of $14 \mathrm{~cm}$ diameter). After a few weeks, nematodes (mainly bacterial feeders and predators) and other benthic organisms penetrated from the detritus and the untreated sediment into the agar. With this procedure, developed by Maertens (unpubl.), we were able to maintain the nematodes for more than 3 months at room-temperature. From these cultures we established monospecific subcultures by transferring gravid females of a single species into smaller Petri dishes (3.5 cm diameter) with enriched bacto-agar (see below).

\section{Medium}

The medium for the cultures is a $0.8 \%$ sterile bactoagar to which $1 \%$ medium of Vlasblom (pers. comm.) and $0.5-1 \%$ silica is added. The Vlasblom medium has the following constituents: $0.287 \mathrm{~g} \mathrm{FeSO}_{4} \cdot 7 \mathrm{H}_{2} \mathrm{O}_{i} 0.3 \mathrm{~g}$ $\mathrm{NaH}_{2} \mathrm{PO}_{4} \cdot 2 \mathrm{H}_{2} \mathrm{O} ; 30 \mathrm{~g} \mathrm{NaNO} ; 0.47 \mathrm{~g} \mathrm{MnCl}_{2} \cdot 4 \mathrm{H}_{2} \mathrm{O}_{i}$ $50 \mathrm{~g}$ glycine; filled up with distilled water to give $1 \mathrm{l}$. The salinity of the cultures was controlled with a Goldberg $\mathrm{T} / \mathrm{C}$ refractometer $\mathrm{Model}$ 101419. The salinity was maintained between $29 \%$ and $30 \% \mathrm{~S}$ by adding distilled water if necessary. This medium is initially rather viscous, but in time becomes more and more liquid.

\section{Experiments}

We started our experiments with nematodes, adapted to room temperature. During temperature experiments $\left(25^{\circ} \mathrm{C}\right.$ and $\left.20^{\circ} \mathrm{C}\right)$ the nematodes were kept in the dark in a Heraeus incubator type B5042. Embryonic development was followed at $30^{\circ} \mathrm{C}$ and $30 \% \mathrm{~S}$. The eggs were studied in Observation chambers $C$ and $D$, designed and described by Maertens (1975). Observations were made every hour when possible under an inverted microscope. A modified Observation chamber A (Maertens, 1976) was used for microphotography and for measuring the eggs.

\section{RESULTS}

\section{Behavior of Monhystera parelegantula Under Culture Conditions}

Monhystera parelegantula is a small $10.4 \mathrm{~mm}$ length), very active nematode that moves quickly with typical undulatory movements. During locomotion, as well as during periods of inactivity, fast movements of the head were observed. Hopper and Meyers (1966a) described this constant movement of the head of Metoncholaimus sp as 'a seeking for food' or 'an environment-testing' behaviour. $M$. parelegantula is a good swimmer and crosses distances of about $10 \mathrm{~mm}$ in a few seconds. Swimming occurs by violent shaking of the whole body. Although there are no planktonic species, a few nematodes can be considered good swimmers (Stauffer, 1924), and $M$. parelegantula may be placed among these, according to our observations. M. microphthalma, a closely related species also shows excellent swimming abilities in fluid cultures (Vranken, unpubl.). $M$. disjuncta, on the contrary, has poor swimming capacities and contracts and coils its body without directed movements (Vranken, unpubl.).

Gravid females of Monhystera parelegantula deposit eggs in liquid (older cultures with less viscous medium) as well as in solid medium (younger cultures), although the largest concentrations of eggs were always found in the solid agar-medium. Eggs in fluid medium developed normally and juveniles started moving immediately after hatching. However, after a few weeks high mortality of both juveniles and adults was observed in fluid cultures. On the other hand, in a solid agar-substrate juveniles developed well and the new generation of gravid females reproduced well.

The food consisted primarily of unidentified bacteria. In new cultures, the highest concentrations of individuals and eggs were noticed on places with maximum bacterial development. However, aggregations were also observed in older cultures with apparent homogeneous bacterial growth. After gently mixing the medium to destroy the patchiness, new aggregations appeared after sometimes only a few hours. From our observations we conclude that Monhystera parelegantula shows a typical aggregation behaviour under laboratory conditions.

\section{Embryology}

The development of 40 eggs was followed at $30^{\circ} \mathrm{C}$ and $30 \% \mathrm{~S}$. The deposited eggs have a sphericalovoid shape with a mean length and width of respectively $20 \mu \mathrm{m}$ and $26 \mu \mathrm{m}$ ( $\mathrm{n}=72$ ). The eggs are deposited at the single-cell stage with the cytoplasm separated from the egg-shell (Fig. 1.). The granular cytoplasm and the central nucleus are clearly visible. The colour of the eggs changes from dark-brown at the single-cell stage to transparent-grey at the active vermiform stage. This stage can be recognized easily by the active movements of the embryo. Two $h$ after deposition the first cleavage occurs and two inequal 

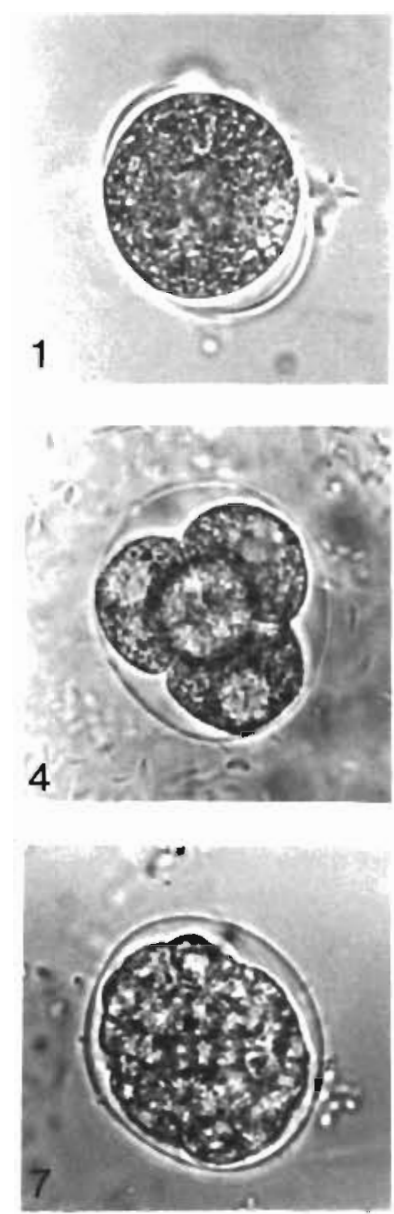

Figs. 1-12. Monhystera parelegantula. Embryonic development (magnification $500 \times)$. 1: 1 -cell stage, 2: 2cell stage; $3: 3$-cell stage; $4: 4$ cell stage; 5 : blastula stage; 6 : gastrulation (invaginationarea indicated by arrow); 7 : later gastrula stage; 8-9: tadpole stage; $10-12$ : active vermiform stage: 11 . typical ring-figure during active vermiform stage

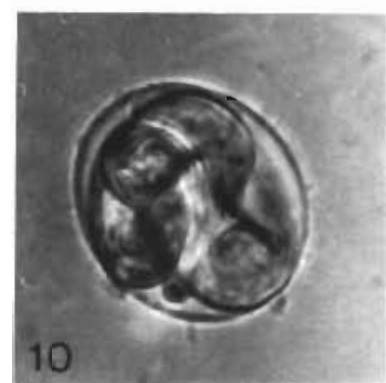

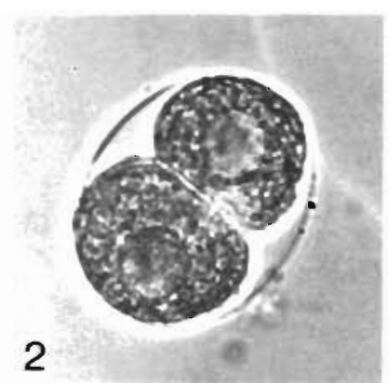
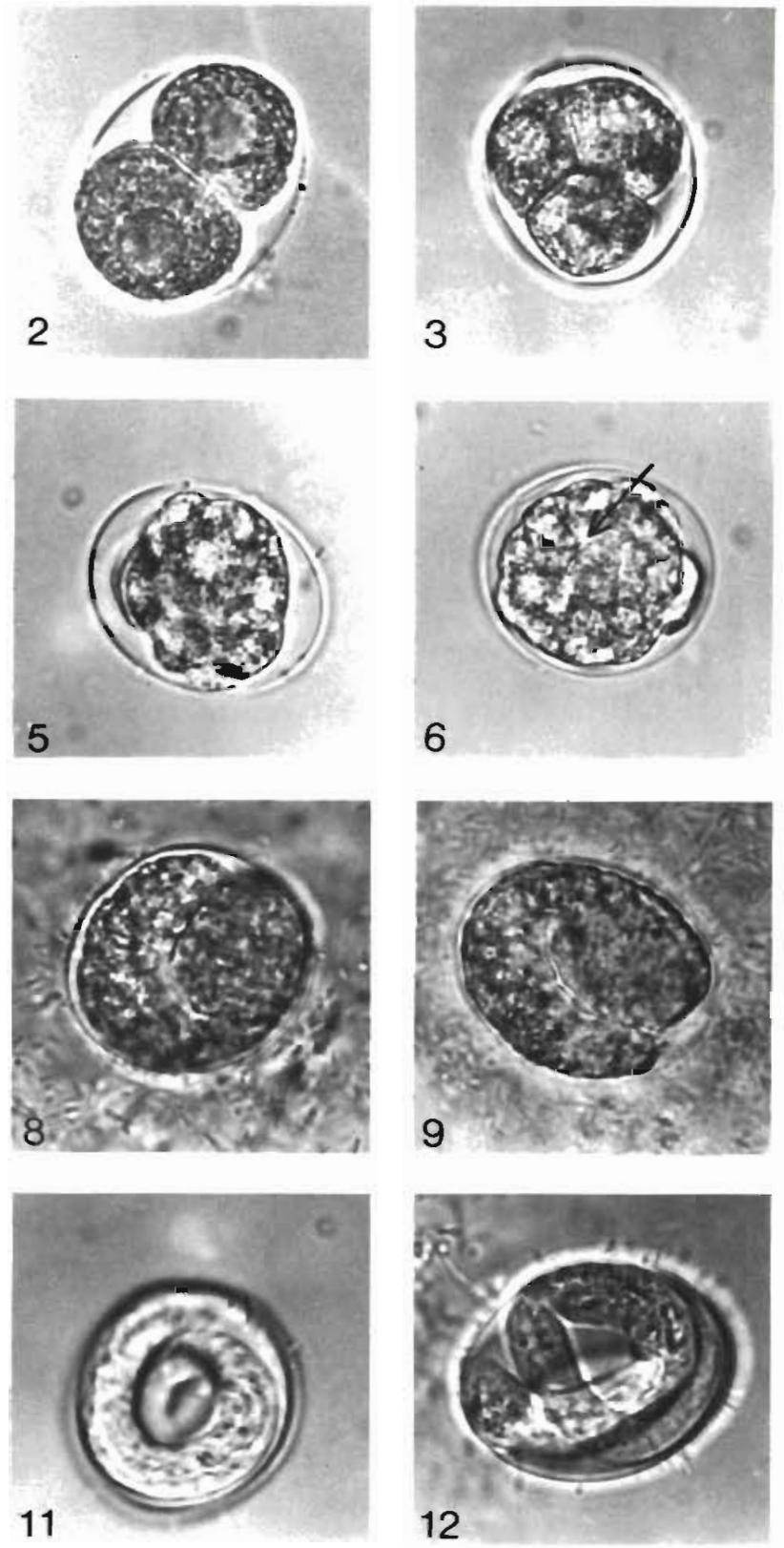

lation starts about $81 / 2$ h after the first cleavage, with a small indention (Figs. 6 and 7), which becomes an oblong slit. Passive rotations of the embryo in the egg shell were observed during gastrulation. After gastrulation a temporary gastrula-tadpole stage is formed which is recognizable by a little groove separating the future head and tail. This temporary stage gives rise to a typical tadpole stage (Figs. 8 and 9) with a thicker end (future head) and a narrower one (future tail). Passive rotations were also noticed during this stage.

After another 7 h the vermiform stage appears and the embryo continues to grow to about twice its original length. Before and during the vermiform stage the ividual cells are difficult to recognize. Further divisions produce an irregular blastula (Fig. 5). Gastru- blastomeres appear (Fig. 2). The cytoplasm is still granular and the nucleus of the largest blastomer meres divides and the 3 -cell stage is reached (Fig. 3). At the 4-cell stage (Fig. 4) slow movements of the This configuration was also observed by Grootaert and Maertens (1976) in Mononchus aquaticus, a predatory nematode. After the 4 -cell stage 


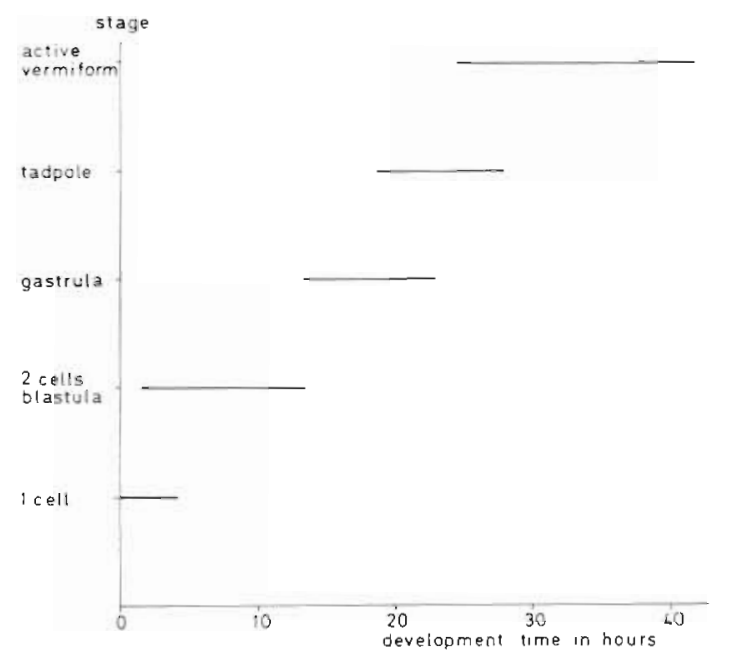

Fig. 13. Monhystera parelegantula. Duration (h) with standard error of cmbryonic development stages at $30^{\circ} \mathrm{C}$ and $30 \% \mathrm{~S}$

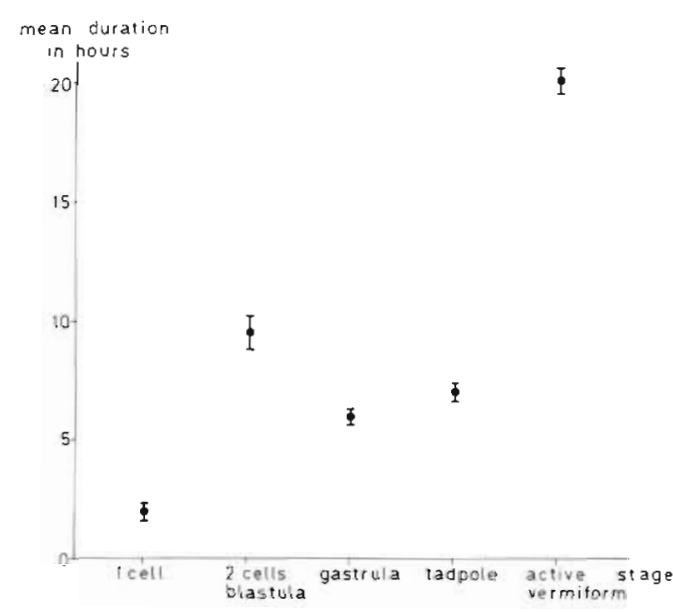

Fig. 14. Monhystera parelegantula. Mean duration (h) with standard error of embryonic development stages at $30^{\circ} \mathrm{C}$ and $30 \% \mathrm{~S}$

Table 1 Monhystera parelegantula. Hatching, juvenile mortality, and duration of different life-cycle stages at $25^{\circ} \mathrm{C}$ and $30 \% \mathrm{~S}$. Range, mean and standard error of 6 experiments, with the number of observed eggs, $N_{t}$ and the number of observed females with eggs, $N$......

\begin{tabular}{|cccc|}
\hline $\begin{array}{c}\text { Embryonic } \\
\text { development } \\
\text { time }(\mathrm{d})\end{array}$ & $\begin{array}{c}\text { Generation } \\
\text { time }(\mathrm{d})\end{array}$ & Hatching & $\begin{array}{c}\text { Juvenile } \\
\text { mortality }\end{array}$ \\
\hline $\begin{array}{c}\text { Range Mean } \\
2-6 \quad 3.8 \pm 0.04\end{array}$ & $\begin{array}{c}\text { Range Mean } \\
8-118.9 \pm 0.04\end{array}$ & $100 \%$ & $0.55 \%$ \\
$\left(\mathrm{~N}_{e}=542\right)$ & $(\mathrm{N}, \ldots e=539)$ & & \\
\hline
\end{tabular}

embryo moves continuously within the egg shell. With these movements a number of different positions are achieved (Figs. 10, 11 and 12), including a typical ring figure (Fig. 11). During the active vermiform stage, lasting about $20 \mathrm{~h}$, the main embryonic length-growth occurs. Juveniles hatch very quickly and immediately start feeding and moving. During embryonic development the shape of the egg shell does not change. At $30^{\circ} \mathrm{C}$ and $30 \% \mathrm{~S}$, the embryonic development of Monhystera parelegantula lasts about $2 \mathrm{~d}$. Fig 13 gives the minimal and maximal time spans for each consecutive stage. Fig. 14 shows mean duration and standard error for every embryonic stage

\section{Post-Embryonic Development and Reproduction}

Post-embryonic growth of Monhystera parelegantula was studied at $25^{\circ} \mathrm{C}$ and $30 \% \mathrm{~S}$. Embryonic development under these conditions takes 2-6 d (average: $3.8 \mathrm{~d}$ ), and hatching is $100 \%$ (Table 1). At the moment of hatching juveniles measure 146-181 $\mu \mathrm{m}$; they are very pale, almost transparent. Fig. 15 illustrates daily length-growth from hatching to sexual maturity. Juvenile mortality under these laboratory conditions was less than $1 \%$

Daily length-growth during post-embryonic development until the gravid-female stage can be calculated with a simple linear equation: $l=160.46$

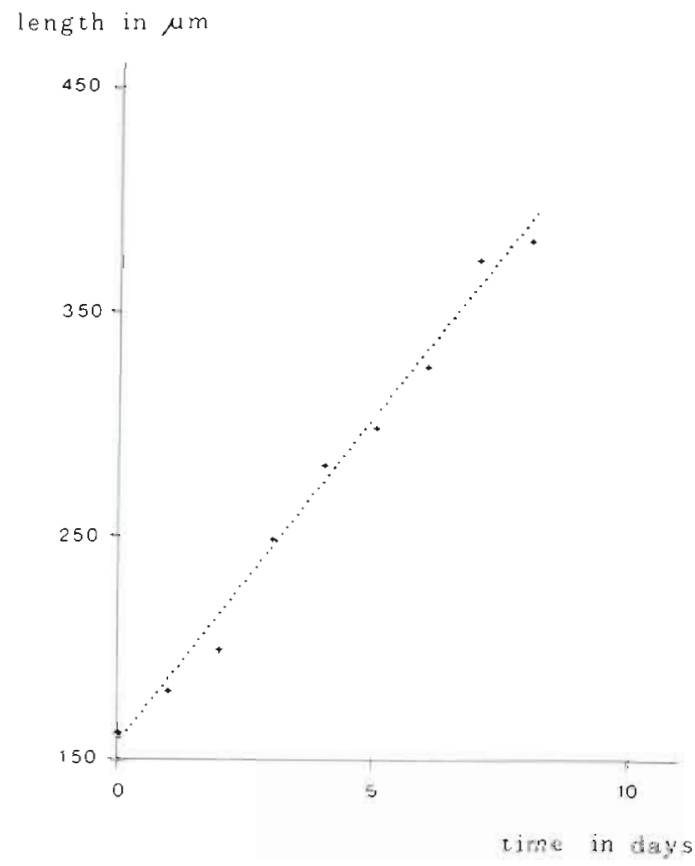

Fig. 15. Monhystera parelegantula. Growth at $25^{\circ} \mathrm{C}$ and $30 \%$ S. Experimental data $(+)$ and growth calculated $(\ldots)$. employing the equation $\}=160.46+29.55\left(t-t_{1}\right)$; see text for details 
$( \pm 3.29)+29.56( \pm 0.55)\left(t-t_{0}\right)$, where $l=$ length in $\mu \mathrm{m}, t=$ time in $\mathrm{d}$, and $t_{1}=$ beginning of post-embryonic development. The first gravid females appear $6 \mathrm{~d}$ after hatching; they have a length of 352-368 $\mu \mathrm{m}$. The mean length increment between the seventh and eighth day is only $10 \mu \mathrm{m}$. On Day 8 nearly all females carry one large shelled egg in the uterus; their length varies between $343-414 \mu \mathrm{m}$, whereas older females (exact age unknown) attain 375-455 $\mu \mathrm{m}$. This clearly shows the existence of adult length-growth, although it is proportionally small. Nevertheless the main growth in length occurs during the post-embryonic stage

Mean generation time is $8.9 \mathrm{~d}$, calculated as the time span between a female of the first generation with a well-developed egg in the uterus and a second generation female at a similar stage. Gravid females normally carry only 1 shelled egg in the uterus, but near the end of their life there may be 2 or 3 such eggs in the uterus.

Reproduction of Monhystera parelegantula under laboratory conditions is parthenogenetic; only 1 male was found during more than 20 successive generations.

\section{DISCUSSION}

Although Monhystera parelegantula is an excellent swimmer, it prefers a solid medium. In a liquid medium the nematodes swim around too actively probably in search of a substratum; this results in a higher mortality, both among juveniles and adults. Preference for a more viscous medium is easily observed by putting some small lumps of denser agar in the fluid medium: the nematodes immediately aggregate in this substrate. The optimal medium appears to be agar of $0.6-0.8 \%$. A $0.8 \%$ agar was preferred here because a $0.6 \%$ agar rapidly turns into a liquid state. The nematodes penetrate only with difficulty into more solid media, such as $1 \%$ agar; their activity decreases and gravid females can only move with great difficulty.

Monhystera parelegantula possesses a funnelshaped, unarmed mouth cavity; according to Wieser's (1953) classification of feeding-types it should be called a non-selective deposit-feeder (Wieser's group 1B). In our cultures unidentified bacteria formed the main foodsource. On a bacterial diet the species is very active; it reproduces well and juvenile mortality is less than $1 \%$. In cultures containing also diatoms and green algae, we have never observed ingestion of these larger food particles. We may therefore conclude that the species feeds on bacteria even though we do not know if bacteria constitute the bulk of the natural diet.

The mode of reproduction in our cultures of Monhystera parelegantula is primarily parthenogenetic; we could maintain a parthenogenetic laboratory population for 20 successive generations. Other studies on cultured populations (Hopper and Meyers, 1966b) and Von Thun (1968), have arrived at the same conclusion.

Nevertheless males do occur, but in the course of our study only 1 male was found, in an old culture with conditions of food shortage, deterioration of the medium and appearance of fungi and yeast cells. There is only 1 record of a male from a population in nature (Timm, 1963). We found at least 10 males immediately after starting a culture with sediment sampled on January 24, 1980 (water temperature $1.5^{\circ} \mathrm{C}$ ), and are confident that these males were collected from nature and not cultivated.

The reason for such a sudden appearance of rare males in the population can only be the subject of speculation. In plant-parasitic nematodes nutrition seems to be involved to some degree in some instances in affecting sexual differentiation (Clark, 1978) and in the terrestrial free-living species Diplenteron potohikus the appearance of rare males was induced by a pheromone-like substance: when the number of eggs in agar-cultures had some intermediate value a larger number of males was produced (Clark, 1978). This has some obvious advantages: when population density is low the metabolite would be absent and all individuals would develop into females which could then rapidly exploit the environment. Indeed, the reproductive potential of a parthenogenetic species is twice as high as that of a sexual species with the same number of progeny. At higher densities some individuals will develop into males, and by sexual reproduction the genetic variability of the population can be maintained. In fluctuating environments sexuality has an advantage because it appears to be a good strategy to produce different kinds of offspring when the environment becomes less predictable (Roughgarden, 1979). It appears from the fossil record that only sexual groups have survived in spite of the fact that an individual female's fitness is twice as high when she reproduces parthenogenetically because in that case her progeny shares $100 \%$ of her genes instead of only $50 \%$ for a sexually reproducing female (Maynard-Smith, 1971). Whether the appearance of rare males will indeed significantly increase genetic variability seems questionable unless only fertilized females reproduce at the time of appearance. In that case density must be low at the start of the next breeding season, and Monhystera parelegantula seems indeed to be a rare species in nature, though it might often be overlooked because of its size.

The embryonic development was studied at the relatively high temperature of $30^{\circ} \mathrm{C}$ because development time is shortest at this temperature. At $25^{\circ} \mathrm{C}$ and $30 \% \mathrm{~S}$, the mean embryonic development time and 
mean generation time are 4 and $9 d$, respectively. Hopper and Meyers (1966b) found that the reproductive cycle of Monhystera parelegantula takes somewhat less than $30 \mathrm{~d}$ in laboratory cultures on seawater-agar and at room temperature. This striking difference in the values of generation time probably stems from differences in culture conditions. Hopper and Meyers (1966b) raised their populations at a lower temperature (room temperature) than we did and used yeast as food source, which - according to our experience - is less suited for culturing the species than bacteria. The resulting difference in generation time stresses the importance of such parameters as temperature, type of food and concentration of agar used for the experiments.

The generation time of Monhystera parelegantula as found by us is comparable to that obtained for other marine monhysterids The following generation times are cited: $13 \mathrm{~d}$ for $M$. disjuncta (temperature varying between $17^{\circ} \mathrm{C}$ and $22^{\circ} \mathrm{C}$, salinity $32 \%$; Gerlach and Schrage, 1971); $10 \mathrm{~d}$ for $\mathrm{M}$. denticulata (at $25^{\circ} \mathrm{C}$ and $26 \% \mathrm{~S}_{i}$ Tietjen and Lee, 1972); $7 \mathrm{~d}$ for Diplolaimel-

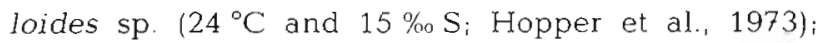
$11.5 \mathrm{~d}$ for Diplolaimella ocellata $\left(24^{\circ} \mathrm{C}\right.$ and $15 \% \mathrm{~S}$; Hopper et al., 1973), and $9 \mathrm{~d}$ for $M$. microphthalma $\left(25^{\circ} \mathrm{C}\right.$ and $20 \% \mathrm{~S}$; Vranken and Heip, unpubl.). It seems that as a rule marine monhysterids tend to have very short reproduction cycles and hence develop several generations per year. Tietjen and Lee (1972) calculated an average of 15 generations per year for $M$ denticulata, while $M$. disjuncta has 12 annual generations, according to Gerlach and Schrage (1971). We calculated for $M$. parelegantula 5 to 5.5 generations per year in the Sluice dock (Vranken and Heip, unpubl.).

In conclusion, Monhystera parelegantula is highly suited for mass-cultivation due to its parthenogenetic mode of reproduction and, like other monhysterids, has a very short life cycle with several generations per year

Acknowledgements. The furst author acknowledges a grant of the Belgian Instıtute for the Encouragement of Scientufic Research in Industry and Agriculture (I. W. O. N. L.), the second author a grant of the Belgian Fund of Collective Fundamental Research (FKFO) grant No. 2.0010.78, the third author a grant 'Bevoegd Verkluturd Navorser' of the Belgian Natıonal Science Foundation (NFWO). The munuscripl benefitted from critical readings by $\mathrm{Dr} D$. Van Damme, Professor Dr. A. Coomans and $Y$ Sharma. We would also like to thank friends of the Marine Biology Section for their support.

\section{LITERATURE CITED}

Barnett, P. R. O. (1968). Distribution and ecology of harpacticoid copepods of an intertidal mudflat. Int. Revue ges. Hydrobiol. Hydrogr. 53: 177-209

Clark, W. C. (1978). Metabolite-mediated density-dependent sex determination in a free-living nematode. Diplenteron potohikus. J. Zool., Lond. 184: 245-254

De Coninck, L. A. P. (1943). Sur quelques especes nouvelles de nématodes libres des eaux et des terres saumâtres de I'Islande. Biol. Jb. Dodonaea 10: 193-220

Gerlach, S. A, Riemann, F. (1973). The Bremerhaven checklist of aquatic nematodes. Veröf. Inst. Meeresforsch. Bremerh. 4 (Suppl.): 1--404

Gerlach, S. A., Schrage, M. (1971). Life cycles in marine meiobenthos. Experiments at various temperatures with Monhystera disjuncta and Theristus pertenuis (Nematoda). Mar Biol. 9: 274-280

Govaere, J. C. R., Thielemans, L. K. (1979). A simple device for taking undisturbed meiobenthic samples in shallow water. Biol. Jb. Dodonaea 47: 137-139

Grootaert P. Maertens: D. (1976). Cultivation and life cycle of Mononchus aquaticus. Nematologicd 22: 173-181

Hopper, B. E. Fell, J. W.. Cefalu, R. C. (1973). Effect of temperature on life cycles of nematodes associated with the mangrove (Rhizophora mangle) detrital system. Mar Biol. 23: 293-296

Hopper, B. E., Meyers, S. P. (1966a). Observations on the bionomics of the marine nematode, Metoncholaimus sp. Nature, Lond. 209: 899-900

Hopper, B. E., Meyers, S. P. (1966b). Aspects of the life cycle of marine nematodes. Helgoländer wiss. Meeresunters. 13: $444 \cdot 449$

Kınne, O. (1977). Cultivation of anımals: research cultivation. In: .O. Kinne (ed.) Marine ecology, Vol. III, Cultivation, Part 2. Wiley, Chichester, pp. 579-1293

Maertens, D. (1976). Observations on the life cycle of Prionchulus punctatus (Cobb) and culture conditions. Biol. Jb. Dodonaea 43: 197-218

Maynard-Smith, J. (1971). The origin and maintenance of sex. In: Williams, G. C. (ed.) Aldin Publishing Company, Chicago, pp. 163-175

Roughgarden, J. (1979). Theory of population genetics and evolutionary ecology: an introduction, McMillan Publishing Co., New York

Schuurmans Stekhoven, J. H., Jr. (1942). Les nématodes libres marins du bassin de chasse d'Ostende. Bull. Inst. r. sci. nat. Belg. 18: 1-26

Stauffer, H (1924). Die Lokomotion der Nematoden. Zool. Jb. 49: $1-118$

Thun, W. von (1968). Autökologische Untersuchungen an freilebenden Nematoden des Brackwassers, Ph. D. thesis, University of Kiel

Tietjen, J. H., Lee, J. J. (1972). Life cycles of marine nematodes. Influence of temperature and salinity on the development of Monhystera denticulata TIMM. Oecologia (Berl.) 10: 167-176

Timm, R. W. (1963). Marine nematodes of the suborder Monhysterina from the Arabian Sea at Karachi. Proc. helminth. Soc. Wash. 30(1): 34-49

Wieser, W. (1953). Die Beziehung zwischen Mundhöhlengestalt, Ernährungsweise und Vorkommen bei freilebenden marinen Nematoden. Ark. Zool. 4: 439-484. 